\title{
DESCRIÇÃO DA POBREZA RURAL NO BRASIL: UMA ANÁLISE DE 2003 E 2009
}

\author{
Thaís Damasceno Lima' \\ Stephano Hertal Farias Nunes ${ }^{2}$
}

\section{Resumo}

Este trabalho tem por objetivo descrever a pobreza na área rural no Brasil utilizando-se de dados e mapas que subsidiam a análise dos anos de 2003 a 2009. Para tanto, são apresentadas as diversas abordagens e conceitos de pobreza e sua mensuração. Em seguida parte-se para o estudo de caso do Brasil, tendo como principal foco a insuficiência de renda e a insuficiência alimentar. Por fim faz-se uma análise crítica dos dados colocando em pauta os programas assistencialistas que podem ter ajudado na diminuição da pobreza na zona rural. Segundo relatório da ONU, a maioria dos pobres do mundo se situam nessa área.

Palavras-chave: Pobreza Rural; Renda; Brasil.

Classificação JEL: I3, I32, I38, O1, O15, O18.

\section{INTRODUÇÃO}

Dado o crescimento paulatino da preocupação da pobreza como um problema social, há uma necessidade de defini-la. Porém, deve-se considerar que "a definição de pobreza e de uma linha de pobreza envolve amplo debate

Graduada em ciências econômicas pela Universidade Federal de Uberlândia, mestranda do programa de Pós Graduação em Economia da Universidade Estadual Paulista "Júlio de Mesquita Filho" (PPGE/Unesp). Email: thaistdl@hotmail.com

2 Graduado em economia pela Universidade Estadual de Maringá, mestrando do programa de Pós Graduação em Economia da Universidade Estadual Paulista "Júlio de Mesquita Filho" (PPGE/Unesp) com bolsa de apoio da Capes e professor colaborador do Departamento de Economia da Universidade Estadual de Ponta Grossa. 
entre os pesquisadores da denominada "área social" no Brasil" (RIBEIRO; NEDER , 2009, p. 483). Ao longo do tempo foram cunhadas divergentes percepções de pobreza. Atualmente, há a coexistência de diversas formas de compreensão desse problema social seja na esfera da observação e estudo do problema, seja no âmbito da realização de intervenções de políticas públicas.

Pobreza é um termo que remete à carência relativa de algum atributo de um ente, seja um indivíduo, uma região ou país. No meio científico é necessária uma definição mais precisa tanto do atributo utilizado para caracterizar o estado de pobreza como do nível de carência a partir do qual se consideraria uma pessoa, família, região ou país como pobre. É preciso considerar que a pobreza é um fenômeno multidimensional que, portanto, não está relacionado apenas a variáveis econômicas, mas também a variáveis culturais e políticas. Ainda segundo o relatório Pobreza Rural 2011, divulgado pela Organização das Nações Unidas (ONU), mesmo com a significativa diminuição da pobreza na zona rural, é nesta área que a maioria dos pobres no mundo continua vivendo.

No meio rural torna-se imprescindível atentar-se aos rendimentos tanto monetários, como, principalmente, os não monetários no estudo da pobreza. Estes rendimentos não monetários advêm das atividades de produção para o autoconsumo e tendem a ser maiores quanto maior for o estado de privação econômica das famílias. Ressalta-se aí a dificuldade de mensuração desta parcela da renda. Desta forma, os indicadores de pobreza para as áreas rurais baseados estritamente na condição de insuficiência de renda tendem a superestimar a quantidade de pessoas e domicílios pobres.

Para Sen (2000) a expansão das capacitações do indivíduo trazem como consequência o aumento da renda deste indivíduo, reduzindo, dessa forma, a pobreza. Com base nessa perspectiva, apesar de um possível aumento do PIB não ser condição única suficiente para melhorar a vida dos indivíduos, ele é necessário para tanto. Como fator de diminuição da pobreza, o crescimento do PIB deve ser redistributivo. Para isso, são necessárias políticas públicas formuladas para atuar sobre a redistribuição da renda na tentativa de reduzir as desigualdades. $\mathrm{O}$ autor acredita que as políticas públicas devem ser voltadas para ampliar as capacidades humanas, e redistribuir os ganhos auferidos de um crescimento econômico. 
Durante os anos de 2003 a 2009 a pobreza no campo diminuiu cerca de 30 pontos percentuais. Parte da queda é atribuída ao êxodo da população campesina para as cidades e às políticas públicas específicas à popolação rural, tais como o PRONAF e apliação ao direito de aposentadoria. Apesar do aumento das políticas públicas de assistência social e de ampliação dos benefícios previdenciários, ainda constata-se no Brasil uma situação de persistência da pobreza rural. Este artigo tem por objetivo retratar ações e fatos relativos à questão da pobreza no campo e aprofundar a análise dos determinantes da reprodução da pobreza rural. Alguns determinantes são clássicos, como os que creditam enfaticamente a persistência da pobreza devido à concentração da propriedade da terra no Brasil. Ao restringir o acesso da população rural ao recurso essencial para a superação do estado de pobreza, resulta em uma estrutura de poder político dominado pelas oligarquias agrárias que travam o desenvolvimento rural inclusivo.

O método escolhido para cumprir com o objetivo foi uma análise de dados como: taxa de pobreza, insuficiência de renda, insuficiência alimentar, ocupação dos indivíduos no agupamento agrícola e as trajetórias gráficas da renda, pobreza e da desigualdade. Estes indicadores auxiliaram para a formação do retrato da situação da pobreza no campo nos períodos recentes. Além dessa introdução o artigo conta com mais três seções e a conclusão. $\mathrm{Na}$ seção dois e três são apresentados o conceito de pobreza e suas formas de mensuração. Na seção de número quatro a pobreza é contextualizada à realidade brasileira nos anos recentes, e dados do período de ações e politicas públicas assistenciais são observados e analisados. Por fim, tem-se a conclusão desse estudo.

\section{AS ABORDAGENS CONCEITUAIS DA POBREZA}

Em campanhas políticas brasileiras tornou-se cada vez mais comum abordar o tema da pobreza dando enfoque nas desigualdades sociais existentes no país. O Brasil vem se preocupando com a persistência da pobreza desde o início da década de noventa, e o tema ganhou ainda mais destaque após a estabilização da inflação, passando a ser até hoje a principal inquietude brasileira (ROCHA, 2003). 
Assim, torna-se míster uma explanação primária do significado de pobreza. Porém é importante ressaltar que a definição da pobreza assim como sua mensuração constitui-se num campo de pesquisa tão amplo quanto antigo. Conceitualmente a palavra pobreza refere-se a miséria, penúria, indigência. É pobre aquele desprovido ou mal provido do necessário; pessoa que vive em estado de necessidade. A pobreza é tida como um termo que remete à carência relativa de algum atributo de um indivíduo, região ou país. Porém, deve-se compreendê-la como um fenômeno complexo, no qual deve ser levado em conta todo o contexto econômico, político e social no determinado tempo em que se tenta definí-lo.

A pobreza e, portanto, as carências que os indivíduos que nela se enquadram possuem, acaba se refletindo na dieta alimentar, com ingestão uma alimentação de baixo valor nutricional, como também se reflete na maneira de vestir, nas condições habitacionais e sanitárias, e até nas oportunidades de emprego. Essas carências vão além do campo material. A pobreza também se reflete nas altas taxas de analfabetismo, baixa expectativa de vida, elevada taxa de mortalidade infantil, e a falta de acesso à infraestrutura básica necessária à reprodução da vida humana em sociedade.

Dessa forma, uma abordagem que visa a definição de pobreza é o conceito da não satisfação de necessidades básicas (SALAMA \& DESTREMAU, 1999). Considerando essencial o acesso a alguns bens, de forma que sem estes os indivíduos estariam impossibilitados de usufruirem uma vida digna. São considerados: o acesso a água potável, rede de esgotos, coleta de lixo, acesso à educação e ao transporte coletivo bens necessários à inserção social do indivíduo e à manutenção de uma vida saudável.

Vê-se portanto que deve ser buscado não apenas a definição de pobreza como também das necessidades dos indivíduos pobres. A privação à qual se refere a noção de pobreza pode ser não só material, como também social e cultural. Logo, ao incluir além dos aspectos econômicos, os aspectos político-sociais e culturais, deve-se considerar a pobreza como uma variável multidimensional (KAGEYAMA; HOFFMANN, 2006).

Com base nisso, de acordo com Hagenaars e De Vos (1988) há três categorias nas quais pode-se enquadrar a pobreza:

i) Pobreza absoluta: nesta categoria a pobreza é definida como o fato de ter menos do que um mínimo definido objetivamente. 
ii) Pobreza relativa: conceituado como se ter menos do que outros na sociedade.

iii) Pobreza subjetiva: na qual pobreza é sentir que não se tem o suficiente para seguir adiante.

Entre as formas de medição temos tanto as formas absolutas, como também as relativas e subjetivas como demostrado por Hagenaars e De Vos (1988) e Kageyama \& Hoffmann(2006). No meio científico exige-se uma definição mais precisa tanto do atributo utilizado para caracterizar o estado de pobreza como do nível de carência a partir do qual se consideraria uma pessoa, família ou região como pobre.

\section{ALGUMAS FORMAS DE MENSURAÇÃO DA POBREZA}

No Brasil, as definições das linhas de pobreza têm sido várias, indo de salários mínimos e renda diária até consumo diário de calorias e proteínas necessárias para manter um padrão mínimo de nutrição.

$\mathrm{Na}$ ótica da renda, denomina-se linha de pobreza um valor estabelecido a priori no qual todos os indivíduos que possuem renda igual ou menor do que tal valor pode ser classificado como pobre. Dentro dessa visão, é importante ressaltar a linha de pobreza estabelecida pelo Banco Mundial de U\$1,00/dia, ou seja, todos aqueles que ganham um dólar por dia ou menos são caracterizados como pobres. Há também a linha de pobreza utilizada pela CEPAL e por Hoffmann (2001) que é de e do salário mínimo, classificando reciprocamente como pobre e pobre extremo. Torna-se importante ressaltar que outra forma de se traçar uma linha de pobreza é adotando os critérios de elegibilidade das políticas públicas de combate à pobreza como o Fome Zero e o Bolsa Família.

Ainda sobre a renda, o Atlas do Desenvolvimento Humano (2000) e Helfand e Levine (2006) utilizam a fixação do salário mínimo considerando que aqueles que possuem renda abaixo do valor estimado como salário mínimo pode ser caracterizado como aquele que não possui recursos para adquirir o básico estimado para suprir as necessidades individuais.

Seguindo a mesma visão de determinação de uma linha de pobreza pela renda, Graziano da Silva et al. (2000) apresentam como alvitre uma metodologia que se baseia na renda total declarada na Pesquisa Nacional 
por Amostra de Domicílios do ano de 1999, considerando o valor estimado para o autoconsumo familiar agrícola (somado à renda declarada) e o valor do aluguel e da prestação da casa própria pagos (descontado da renda declarada). O valor obtido é o que o autor chama de renda média familiar desponível per capita e é comparado com a linha de pobreza de U\$ 1,08 por dia, adotada para as áreas rurais do Nordeste e corrigidas para as demais áreas pelos índices de custo de vida regional do país.

Como já mensionado, é bastante complexo definir um significado de pobreza, assim como mensurar e traçar uma linha que possa dimensioná -la. Na literatura sobre indicadores sociais de que as definições de pobreza baseadas unicamente na renda podem ser insuficientes para caracterizar a população pobre. Isso porque a pobreza não está relacionada apenas a fatores econômicos, mas também a fatores políticos, sociais e culturais, identificando assim uma pobreza de caráter multidimensional.

Com base no enfoque multidimensional da pobreza, Hoffmann e Kageyama(2006) traçaram uma classificação entre pobres e não pobres utilizando uma combinação entre nível de renda e acesso/disponibilidade de três ítens básicos de infraestrutura: a presença de água canalizada em no mínimo um comodo, a existência de banheiro no domicílio ou na propriedade e a presença de luz elétrica no domićlio. Com essa base traçou-se dois níveis de renda como linhas de pobreza. Uma correspondente à metade do salário mínimo vigente no mês de maio de 2005, que se refere ao valor de $\mathrm{R} \$ 150,00$, e outra correspondente à do salário mínimo da mesma data, o que corresponde ao valor de $\mathrm{R} \$ 75,00$. Foram considerados também os rendimentos levantados pela PNAD, utilizando como referência o mês de setembro de cada ano e inflacionando-os para atualização dos valores para todo o período estudado. Dessa forma, a pobreza é definida combinando a linha de pobreza e a existência dos itens considerados básicos de infraestrutura. Assim classificou-se como:

- Não pobre: aquele com renda demiciliar per capita acima da linha de pobreza e que possui no mínimo dois dos três itens de infraestrutura considerados na pesquisa.

- $\quad$ Pobre tipo II: aqueles que possuem renda acima da linha de pobreza e que vivem em domicílios com menos de dois dos itens de infraestrutura. 
- Pobre tipo I: o indivíduo com renda abaixo da linha de pobreza e com um dos três ítens de infraestrutura considerados.

- Extrema pobreza: o individuo com renda abaixo da linha de pobreza definida e cujo domicílio não possui nenhum dos três ítens de infraestrutura considerados como básicos na pesquisa realizada.

$\mathrm{Na}$ tentativa de conceituar e dimensionar economicamente a pobreza rural, leva-se em consideração que na análise de Chambers (2006) classifica os critérios desse dimensionamento em quatro diferentes grupos:

O primeiro é renda-pobreza, que define a pobreza segundo a renda ou consumo, baseada em um valor pré-estabelecido para a renda ou nível de consumo.

O segundo vincula-se a carências materiais e remete à dimensão subjetiva do desejo. Já que além da renda, a pobreza pode se referir à falta ou insuficiência de riqueza, ou de ativos como casa, roupa, meio de transporte pessoal, televisão, e assim por diante.

O terceiro agrupamento deriva da visão de Amartya Sen, e se expressa como privação de capacidade para realizar projetos pessoais, ou simplesmente desenvolver-se nos padrões sociais. Esta categoria vai além da falta de material ou capacidades humanas, e envolve uma evidente dimensão social e histórica que baliza a importância da privação e qualifica a própria capacidade.

O quarto grupo considera a natureza multidimensional da pobreza, assumindo que o status é influenciado por um ou mais fatores.

Dessa forma, deve-se escolher as dimensões apropriadas e que se relacionam à condição de privação das famílias. Estas dimensões devem ser levadas em consideração no cálculo dos indicadores de pobreza.

Apesar da complexidade que é definir a pobreza, o método mais utilizado para identificar e mensurar a dimensão da pobreza é o da linha de pobreza/indigência, definida em valores monetários com limite variável segundo a pesquisa. No Brasil as linhas definitórias têm sido traçadas a partir de vários critérios, desde salários-mínimos até linhas baseadas em proteínas e calorias necessárias para manter determinado padrão de nutrição (Mattos e Waquil, 2006, p. 4). Enquadra-se neste perfil a linha de pobreza utilizada pelo Banco Mundial (US\$ 1,00/dia) e por Hoffmann (2001) (1/4 e $1 / 2$ do salário mínimo). 
Conforme aponta Diniz \& Arraes (s/d), linhas de pobreza baseadas no consumo observado vêm sendo utilizadas desde a realização do Estudo Nacional da Despesa Familiar (ENDEF- 1974/1975), ganhando novo impulso mais recentemente após a realização das Pesquisas de Orçamentos Familiares (POF) de 1987/1988 e 2002/2003, ambas do IBGE. De fato, as informações destas pesquisas viabilizam a construção de linhas de indigência e pobreza que levam em conta as especificidades das cestas de consumo e alimentares locais.

Rocha, um dos nomes de maior destaque e que mais tem contribuído para a compreensão e mensuração da pobreza no Brasil, utiliza estes indicadores e revela, no trabalho mais recente (2006a), passo a passo de como determinar cinco linhas: 1) Determinação das necessidades nutricionais; 2) Determinação da cesta alimentar; 3) Estimar o consumo não-alimentar; 4) Diferenciar o custo de vida regional; 5) Desenvolvimento das linhas. Para o desenvolvimento das linhas de pobreza regionais Rocha construiu 23 linhas de pobreza e 23 linhas de indigência diferenciadas, de modo a levar em conta tanto as diferenças de custo de vida e de hábitos de consumo entre as áreas urbanas e rurais como entre as regiões brasileiras. Com base nesta metodologia, Rocha (2006) estima em 57,7 milhões de pessoas o número de pobres no Brasil.

Seguindo esta mesma matriz metodológica de dimensionar pobreza pelo nível de renda, Graziano da Silva et. al. (2001) propõe uma metodologia baseada na renda total declarada na PNAD de 1999, corrigida pelo valor estimado para o autoconsumo das famílias agrícolas (somado à renda declarada) e pelo valor do aluguel e da prestação da casa própria pagos (descontado da renda declarada). A renda assim obtida é comparada com a linha de pobreza de US\$1,08 por dia.

Com base em um enfoque multidimensional Buainain, Maletta e Villalobos (1999) definiram a pobreza de uma forma integrada, combinando a carência de renda com a carência de infra-estrutura e serviços básicos nos domicílios. Admitindo cinco tipos de necessidades básicas (abrigo, privacidade, educação das crianças, acesso a sanitário e capacidade de obter uma renda suficiente), os autores consideraram como pobres os domicílios em que pelo menos uma das cinco necessidades básicas não fosse satisfeita. 
É importante ressaltar que uma análise da situação de pobreza rural com enfoque multidimensinal mostra que a pobreza rural persiste devido à falta de acesso das populações pobres a condições de vida apropriadas, o que acaba por criar barreiras para o desenvolvimento social e humano para a superação da pobreza extrema. As citadas dimensões referem-se não somente ao acesso a serviços e bens públicos em geral, como acesso a estudo, que permite uma situação que poderá posicionar o indivíduo em uma situação favorável, acesso ao saneamento básico, acesso ao sistema de saúde, etc; como também referem-se à posse de bens de consumo, acesso à terra, condição de moradia, condições favoráveis de trabalho, acesso à agua tratada, energia elétrica e posse de bens de consumo duráveis.

Numa tentativa de diblar o problema das disparidades existentes entre as diversas regiões brasileiras, Silveira et al.(2007) utiliza as informações básicas da Pesquisa de Orçamento Familiar (POF) do IBGE, pesquisa essa que cobre tanto as regiões urbanas, como as metropolitanas e rurais do Brasil, aplicando uma metodolgia que se baseia no parâmetro de requerimentos calóricos necessários ao indivíduo, evitando assim eventuais distorções nas estimativas.

Seguindo a mesma teoria de pobreza multidimensional, Buainain et al. (1999) buscaram definir a pobreza baseando-se em mais de um parâmetro, integrando carência de renda e de infraestrutura e serviços básicos nas residências. Dessa forma, os autores consideraram como necessidades indispensáveis: abrigo, acesso a sanitário, privacidade, educação infantil e capacidade de obtenção de uma renda que seja suficiente para a manutenção familiar. Foram caracterizados como pobres os domicílios nos quais pelo menos uma dessas necessidades não foram atendidas. Tomando como referência essa classificação, no ano de 1995, pelos dados da PNAD, 12 milhões de domicílios, o que em termos populacionais significa $53 \mathrm{mi}$ lhões de pessoas, não alcançavam o padrão de satisfação das necessidades consideradas como indispensáveis nessa pesquisa.

Também com enfoque na infraestrutura e na tentativa de se traçar uma linha de pobreza, Kageyama (2003) aborda uma linha de pobreza de meio salário mínimo vigente no mês de setembro de 2001 para uma renda per capita dos domicílios agrícolas. Dessa forma, combinando também renda e infraestrutura, o autor considera em sua pesquisa: o material de construção 
das residências, o tipo de telhado do domicílio, número de indivíduos residentes por cômodo do domicílio, a presença de água encanada, existência de energia elétrica na residência, o tipo de instalação sanitária, a existência de geladeira, televisão e telefone na residência e a forma de coleta do lixo. $\mathrm{O}$ autor denominou este indicador como Índice de Nível de Vida (INIVI), com ele, cobrem-se as lacunas deixadas pela abordagem unicamente monetária e retratam-se as carências não apenas de renda como também de bem-estar da população.

Segundo De Haan (1999) o conjunto das diversas formas de privação caracterizam o caráter múltiplo e cumulativo das desvantagens sofridas pelos grupos desfavorecidos. Outro autor que defende a visão de caráter multidimensional da pobreza é Mestrum (2002), pois a multidimensionalidade permite que se leve em consideração um número ilimitado de problemas, abrangendo suas causas, consequências e sintomas.

A multidimensionalidade da pobreza para ser mensurada em seu caráter, necessita da construção de um indicador que corresponda à abordagem multidimensional e considere a situação de pobreza auto-avaliada, que é a forma na qual o indivíduo percebe sua própria situação social. Correspondendo a uma abordagem mais abrangente que apenas as necessidades básicas, dado que inclui acesso dos indivíduos à educação, saúde, infra-estrutura, além de compreender a possibilidade dos indivíduos exercerem sua representatividade social e sua cidadania. Assim, pode-se definir a pobreza como a capacidade individual de exercer seus direitos e liberdades, analisando as diversas formas de distribuição e acesso aos recursos coletivos e privados. Esta visão é conhecida como abordagem das capacidades, e ressalta a importância de se observar também os direitos civis e políticos do indivíduo (SEN, 1988).

Sen (2000), adotando a perspectiva das capacitações demonstra que:

Nessa perspectiva, a pobreza deve ser vista como privação de capacidades básicas em vez de meramente como baixo nível de renda, que é o critério tradicional de identificação da pobreza. A perspectiva da pobreza como privação de capacidades não envolve nenhuma negação da idéia sensata de que renda baixa é claramente uma das causas principais da pobreza, pois a falta de renda pode ser uma razão primordial da privação de capacidades de uma pessoa (SEN, 2000, p. 109). 
Emerge dessa abordagem a compreensão das liberdades adotada por Sen (2000), a qual refere-se aos processos que dão liberdade de ações e decisões aos indivíduos da mesma forma como suas oportunidades. A carência da liberdade surge em função de processos ou oportunidades inadequadas que privam algumas pessoas de realizarem o mínimo do que gostariam.

Dessa maneira, torna-se imprescindível que as políticas públicas tomem como finalidade a expansão das liberdades. Os principais meios para conquistar esse objetivo não podem, portanto, se restringir à um aumento na renda, mas sim buscar uma diminuição das desigualdades entre as pessoas e suprir a carência de capacitações, de forma a tornar a educação básica, os serviços de saúde e segurança social acessíveis aos indivíduos, ampliando, assim, a capacitação das pessoas. Dessa maneira, proporciona-se a melhora da qualidade de vida, já que uma expansão das capacitações humanas leva, consequentemente, ao aumento da renda e ajuda a reduzir a pobreza.

Percebe-se, portanto, que há um debate sobre as formas de se definir e mensurar a pobreza. Esse problema social que se mostra cada vez mais em pauta nas discussões não apenas acadêmicas, mas também políticas, envolve distintos e importantes métodos de abordagens. Cada método com suas justificativas e peculiaridades, traz uma discussão não apenas do problema em sí, mas das possíveis causas e soluções a ele atribuída.

\section{POBREZA NO CONTEXTO BRASILEIRO}

O contexto socioeconômico brasileiro teve suas estruturas fortemente alteradas nas duas últimas décadas. Essas transformações incluem mudanças institucionais de forma geral, na estrutura produtiva, assim como nos padrões tecnológicos, e também na dinâmica demográfica. Devido a uma maior interação geográfica, econômica e cultural, o conceito de rural sofreu algumas distorções. Isso, devido ao dinamismo tecnológico que permitiu a criação e o desenvolvimento de uma nova infraestrutura do transporte e meios de comunicação, tornando assim os fluxos populacionais e de informação mais intensos num panorama inter-regional brasileiro.

Não só as políticas públicas sociais de garantia de renda, como também, as políticas de saúde, eletrificação e educação impactaram fortemente sobre as condições de vida da população rural. Além disso, o crescimento 
das pequenas cidades e a renovação da população rural esboça uma aproximação entre campo e cidade, bem como das relações estabelecidas entre essas áreas, com importantes consequências sobre as condições e o modo de vida da população rural.

Recentes análises mostram uma queda da pobreza e a redução da desigualdade econômica no campo. Ao que tudo indica a pobreza rural está sofrendo mudanças estruturais não só na sua caracterização, mas também na sua dinâmica. Deve-se ressaltar, portanto, que a importância social desses movimentos, demonstra uma grande necessidade de maior conhecimento dos processos de transformação no meio rural, estritamente necessário para uma concretização das políticas existentes e para a formulação de novas políticas de intuitos de reforço ao movimento positivo e recente de transformação socioeconômica nas áreas rurais.

Logo, um estudo detalhado dessas especificidades será de suma importância para abrir a possibilidade de que as ações públicas que visam um enfrentamento da pobreza rural tenham uma focalização mais adequada e específica, além de uma diversidade de instrumentos compatíveis com as necessidades e as potencialidades sócioeconômicas presentes no campo.

\subsection{Abordagens de mensuração da pobreza a nível de Brasil}

A pobreza, independente de sua caracterização como absoluta ou multidimensional, possui, no Brasil, a característica de concentração regional. Sabe-se que as desigualdades regionais brasileiras são fortes traços da hitória e do desenvolvimento econômico. Há grande discrepância entre nível de renda, investimento, poupança, tecnologia, alfabetização, entre outros indicadores sociais e econômicos entre as distintas regiões do país.

Segundo Rocha (2010), em países como o Brasil (que possuem nível de renda médio e economia monetizada), para se estabelecer um limite entre pobres e não-pobres, é possível utilizar linhas de pobreza. Ressaltase que a pobreza não é definida apenas como insuficiência de renda. Mas, para uma melhor análise e pela disposição dos dados, as linhas de pobreza formuladas por Rocha (2003), se dá devido às diferenças locais existentes no Brasil. Com essas especificidades busca-se considerar as diferenças nas estruturas de consumo das famílias e de preços ao consumidor das diversas 
regiões, sejam elas metropolitanas, urbanas ou rurais. Para definir as linhas, Rocha (2003) toma como base, de acordo com as pesquisas de orçamento familiar, o consumo entre indivíduos de baixa renda das áreas residenciais das regiões estudadas e, para possibilitar uma análise mais crível, seus valores são anualmente atualizados tendo como referência a variação local dos preços de acordo com grupos de produtos. Esses dados são formulados pela autora utilizando-se de dados da Pesquisa de Orçamento Familiar.

A análise do ano de 2004 torna-se interessante pelo fato de que a partir desse ano há uma evolução do emprego e da renda no Brasil. No período entre 2004 e 2008 (notoriamente um período de crescimento econômico) a taxa média de aumento do Produto Interno Bruto chegou a 4,8\%. Houve também um aumento anual do número de pessoas ocupadas, de cerca de $2 \%$ ao ano durante o quinquênio. Além disso, a recuperação do valor do salário mínimo também foi um fator relevante para o aumento da demanda. A diminuição da taxa de desemprego entre 2004 e 2008 foi um dos aspectos que interferiu no aumento do consumo de $21,5 \%$. O investimento aumentou $44,8 \%$ e as exportações de bens e serviços cresceram $21,2 \%$ durante o período supracitado. A partir de 2004 o crescimento total do montante salarial contribuiu para a retomada do consumo. O sistema financeiro interno aumentou sua credibilidade e ampliou o volume e os prazos de empréstimos para financiar o consumo de bens duráveis. Outros importantes fatores foram os programas de transferência de renda, os quais sofreram forte expansão, sendo imprescindíveis para o aumento do consumo doméstico. $\mathrm{O}$ aumento da demanda efetiva desencadeou o aumento do PIB, que por sua vez provocou uma ampliação das importações em cerca de $81,7 \%$ no período (BALTAR (s/d)).

Dado o relatório da Fundação do Desenvolvimento Administrativo (FUNDAP, 2011), a partir do ano de 2004 a população em idade ativa (PIA) amplia a níveis maiores que a população economicamente ativa (PEA). A população ocupada passa a crescer consideravelmente (no total há um crescimento de $15,6 \%$ entre 2004 e 2009), há o início de uma importante trajetória de queda do desemprego. Entre 2003 e 2010 há um aumento de $7 \%$ dos empregados com carteira assinada, que chega a 2010 a um nível de $51 \%$ da população ocupada. Demonstrando assim uma melhoria dos padrões do mercado de trabalho. 
É imprescindível, portanto, a comparação entre 2004 e 2009, dado que o período 2004-2008 é, notoriamente, um período de crescimento econômico. Além disso, em 2008 o Brasil (e o mundo) começa a sofrer os efeitos da crise norte-americana do subprime, o que é refletido no ano de 2009.

É possível notar um grande avanço na distribuição de renda no Brasil de 2003 para 2009. É importante lembrar que entre 2004 e 2008, o Brasil viveu um momento de crescimento econômico que foi de grande importância para essa melhoria na distribuição dos rendimentos. Deve-se ressaltar também o crescimeto nesses anos dos benefícios sociais e políticas púbicas de combate a pobreza (ROCHA, 2010). Percebe-se, contudo, que o nordeste ainda em 2009 se encontra como uma área crítica, possuindo três estados com cerca de $30 \%$ das pessoas com insuficiência de renda, sendo que essa insuficiência se agrava na área rural.

$\mathrm{Na}$ figura 1, pode-se evidenciar a pobreza por região mais afetada. Pode-se perceber que a incidência de pobreza (indivíduos com renda per capita entre $\mathrm{R} \$ 70,00$ e $\mathrm{R} \$ 140,00)$ e indigência (indivíduos com renda até $\mathrm{R} \$ 70,00$ per capita) na região norte e nordeste é consideravelmente maior que nas demais regiões. Enfatiza-se principalmente a região nordeste, a qual em 2009 apresenta cerca de 7,2 milões de indigentes e 9,4 milhões de pobres, números considerados alarmantes.

Figura 1 - Percentual e número absuluto de indivíduos em situação de pobreza e indigência no Brasil em 2009 por região

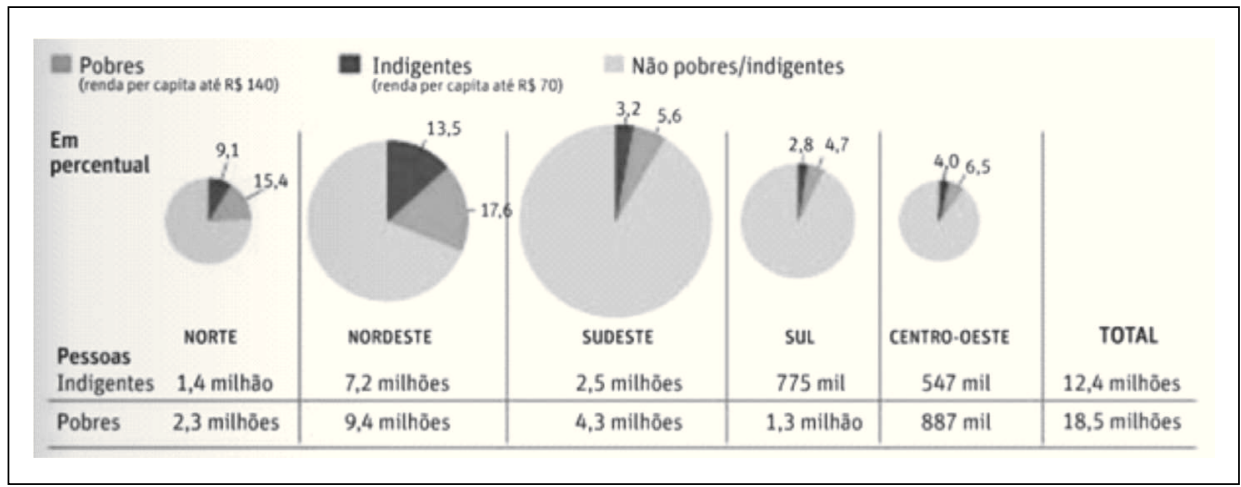

Fonte: Costa, 2010. 
Segundo o Fundo Internacional de Desenvolvimento Agrícola (FIDA relatório de Novembro de 2011), o Nordeste brasileiro é a região com maior índice de pobreza rural da América Latina. O relatório ainda ressalta que os agricultores em situações preocupantes, os quais ainda conseguem manter sua subsistência, porém com dificuldades, dependem do clima da região, na qual a perda da lavoura é uma situação que ocorre frequentemente. Além disso, atenta-se para o fato de que uma das principais causas da pobreza no Brasil, e principalmente nessa região é a desigualdade da posse de terras. As terras cultiváveis estão concentradas nas mãos de poucos proprietários.

Outrossim, o FIDA atenta para o fato de que no Nordeste há um cenário degradante de baixa renda, condições climáticas desfavoráveis, limitação dos recursos naturais, além do precário acesso aos serviços públicos. Salienta-se que o atraso das populações rurais, em muitas vezes, se dá também pelo alto índice de analfabetismo, limitado acesso à infraestrutura e acesso a serviços básicos como água tratada, saneamento básico, atendimento médico. No tocante ao acesso à água, é grande o número de indivíduos no Nordeste, principalmente, que carece de acesso a esse bem.

No gráfico da figura 2, percebe-se a problemática nordestina da pobreza no Brasil. Nota-se que esse não é um problema recente e que a desigualdade sofreu uma atenuação ao longo do tempo. Porém, como ressalta o relatório da FIDA, a região Nordeste continua sendo a região brasileira com maior incidência de pobreza e pobreza extrema (indigência).

Mesmo com um notório avanço da economia brasileira e uma diminuição considerável da pobreza e pobreza extrema nas regiões, o Nordeste é ainda a região, em 2008, com o maior índice de pobreza. Porém, deve-se considerar uma diminuição de cerca de quase 30 pontos percentuais na diminuição da pobreza entre 1995 e 2008 e uma redução em cerca de quase 25 pontos percentuais na taxa de pobreza extrema nordestina entre esses mesmos anos.

As regiões Sul e Sudeste concentram em 2008 os menores índices de pobreza e pobreza extrema do país. Sendo que esses índices em 2008 diminuíram para cerca da metade do que eram em 1995. No Norte, assim como no Nordeste, a taxa de pobreza e pobreza extrema ainda são preocupantes, sendo a taxa de pobreza extrema cerca de 5 pontos percentuais abaixo da taxa de pobreza, que por sua vez é de 22,8\% em 2008. 
Figura 2 - Taxa de pobreza aboluta e de pobreza extrema nas regiões brasileiras nos anos de 1995 e 2008

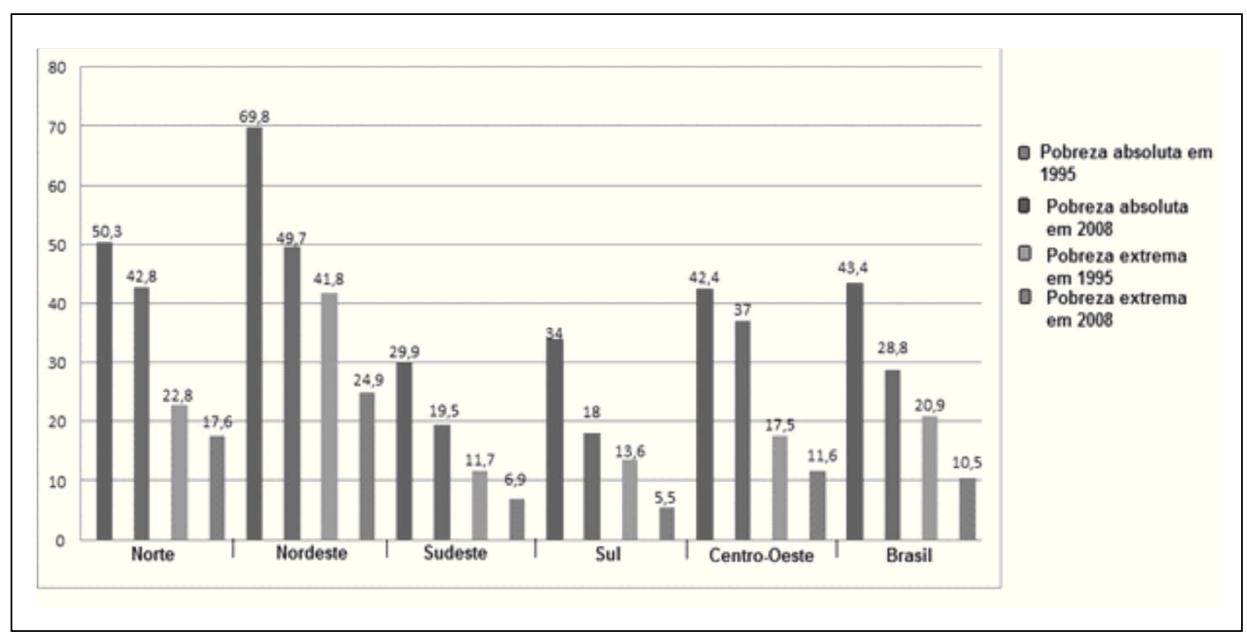

Fonte: IPEA

Na figura 3, por sua vez, são caracterizados os indivíduos que sofrem com a insuficiência alimentar, esses indivíduos são, portanto, aqueles que não conseguem sequer, auferir o mínimo necessário para a sobrevivência. A insuficiência alimentar é caracterizada pela não ingestão da quantidade mínima de nutrientes necessários para a manutenção da vida humana, de forma a suprir as necessidades energéticas do indivíduo dado o papel social que ele possui na população em que vive.

Assim como na figura 3, na figura 4 a distribuição regional em percentual das pessoas que se encontram em estado de insuficiência alimentar é indicado pelas cores, e o número real de pessoas que se encontram nesse em meio a esse problema é representado pelos círculos. 
Figura 3 - Distribuição espacial da insuficiência de renda no Brasil nos anos de 2003 e 2009

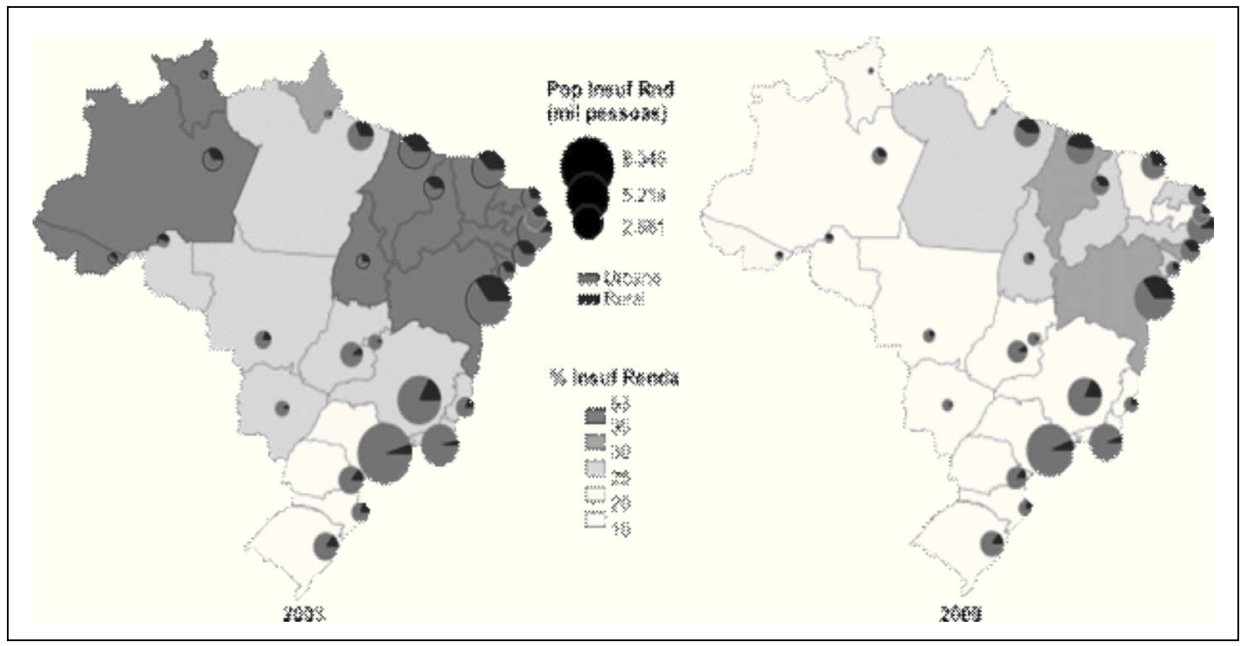

Fonte: Maia; Buainain, 2011.

Figura 4 - Distribuição espacial da insuficiência alimentar no Brasil nos anos de 2003 e 2009

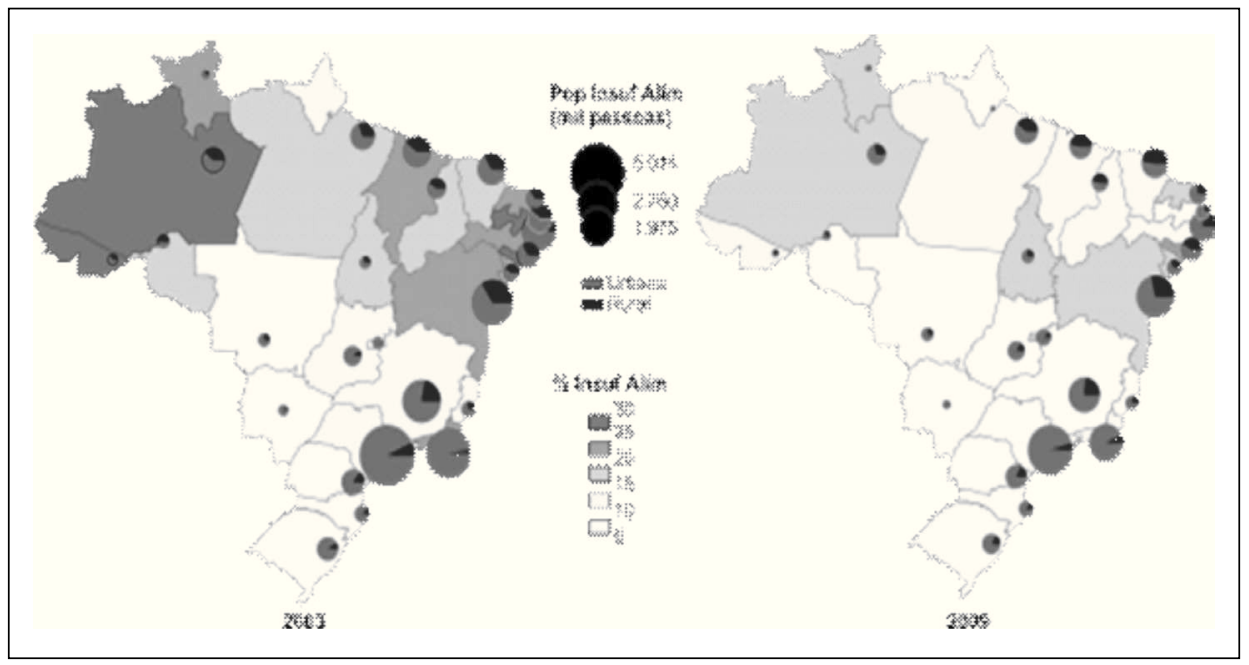

Fonte: MAIA; BUAINAIN, 2011. Acesso em 15 jan. 2013. 
No tocante à insuficiência alimentar, há uma continuidade da tendência de concentração do problema. Sendo, portanto, as regiões Norte e Nordeste as mais afetadas com essa insuficiência. Os estados do Acre, Amazonas, Paraíba e Alagoas são os que apresentam uma maior porcentagem de indivíduos com insuficiência alimentar em 2003. Em 2009, nota-se uma melhora no problema de insuficiência alimentar, entretanto, as regiões Norte e Nordeste continua como as mais afetadas pelo problema. Sendo o estado de Alagoas a região com maior índice de pessoas com insuficiência alimentar no Brasil no ano de 2009. Há também uma continuidade da proporção de pessoas com insuficiência alimentar na área rural.

Tabela 1- Distribuição da população (\%) segundo indicadores autodeclarados de insuficiência de renda e de alimentos - Brasil 2003 e 2009

\begin{tabular}{|l|r|r|r|r|r|r|r|r|}
\hline \multirow{2}{*}{ Indicador de qualidade de vida } & \multicolumn{3}{|c|}{$\mathbf{2 0 0 3}$} & \multicolumn{3}{c|}{$\mathbf{2 0 0 9}$} \\
\cline { 2 - 9 } & \multicolumn{2}{|c|}{ Urbano } & \multicolumn{2}{c|}{ Rural } & \multicolumn{2}{c|}{ Urbano } & \multicolumn{2}{c|}{ Rural } \\
\cline { 2 - 9 } & N (1.000) & \% & N (1.000) & \% & N (1.000) & \% & N (1.000) & \% \\
\hline Renda permite que se viva com: & & & & & & & & \\
\hline Muita Dificuldade & 40.491 & 28 & 11.271 & 38 & 29.065 & 19 & 8.037 & 25 \\
\hline Dificuldade & 34.682 & 24 & 7.676 & 26 & 33.972 & 22 & 8.435 & 26 \\
\hline Alguma dificuldade & 49.447 & 34 & 8.258 & 28 & 56.776 & 37 & 10.577 & 33 \\
\hline Alguma facilidade & 12.015 & 8 & 1.625 & 5 & 20.778 & 13 & 3.297 & 10 \\
\hline Facilidade & 5.946 & 4 & 786 & 3 & 13.508 & 9 & 1.667 & 5 \\
\hline Muita Facilidade & 864 & 1 & 146 & 0 & 1.323 & 1 & 186 & 1 \\
\hline & & & & & & & & \\
\hline Quantidade de alimentos: & & & & & & & & \\
\hline Normalmente não é suficiente & 21.720 & 15 & 5.881 & 20 & 15.306 & 10 & 4.474 & 14 \\
\hline Às vezes não é suficiente & 48.406 & 34 & 12.544 & 42 & 43.230 & 28 & 11.663 & 36 \\
\hline É sempre suficiente & 73.156 & 51 & 11.340 & 38 & 96.858 & 62 & 16.052 & 50 \\
\hline
\end{tabular}

Fonte: MAIA; BUAINAIN, 2011. Acesso em 28 jan. 2013.

Na tabela 1 pode-se perceber a quantidade de indivíduos que possuem grande dificuldade em viver com a renda auferida, tanto na área urbana quanto na área rural. Em 2003 mais de 28\% da população urbana enfrentava o problema de insuficiência de renda, enquanto que $38 \%$ da população rural se deparavam com o mesmo problema. Em 2009 há uma melhora signifi- 
cativa nesse percentual, passando para $19 \%$ da população urbana e $25 \%$ da população rural com insuficiência de renda. No que tange à insuficiência alimentar, em 2003 15\% e 20\% da população urbana e rural, respectivamente, enfrentavam a problemática da insuficiência alimentar, enquanto que em 2009 esse número baixou para 10\% da população urbana e 14\% da população rural. Nota-se, assim, uma melhora significante nas duas zonas, sendo notório em 2009 o quanto a área rural ainda tem uma maior porcentagem populacional, quando comparada à área urbana, enfrentando a pobreza tanto no tocante à insuficiência de renda quanto da insuficiência alimentar.

Em relação à pobreza rural, faz-se necessária uma análise do mercado de trabalho agrícola. Dessa forma, a figura 3 evidencía a situação do trabalho no agrupamento agrícola. Nota-se que há quatro categorias distintas no gráfico, são elas: empregados, trabalhadores por conta-própria, empregadores e trabalhadores não reunerados. A menor categoria, abrangendo apenas $3 \%$ da população brasileira desse agrupamento é a de empregadores. Ainda no agrupamento agrícola, 25\% são trrabalhadores por conta-própria (muitos deles agricultores familiares que podem ser beneficiados pelo PRONAF), $29 \%$ são empregados e a grande maioria $43 \%$ são trabalhadores não remunerados (nessa categoria se enquadra os indivíduos que trabalham na agricultura familiar sem remuneração, trabalhando para a própria família, ou aqueles indivíduos que trabalham apenas para subsistência).

Figura 5 - Posição na ocupação do indivíduo ocupado em empreendimento do agrupamento agrícola

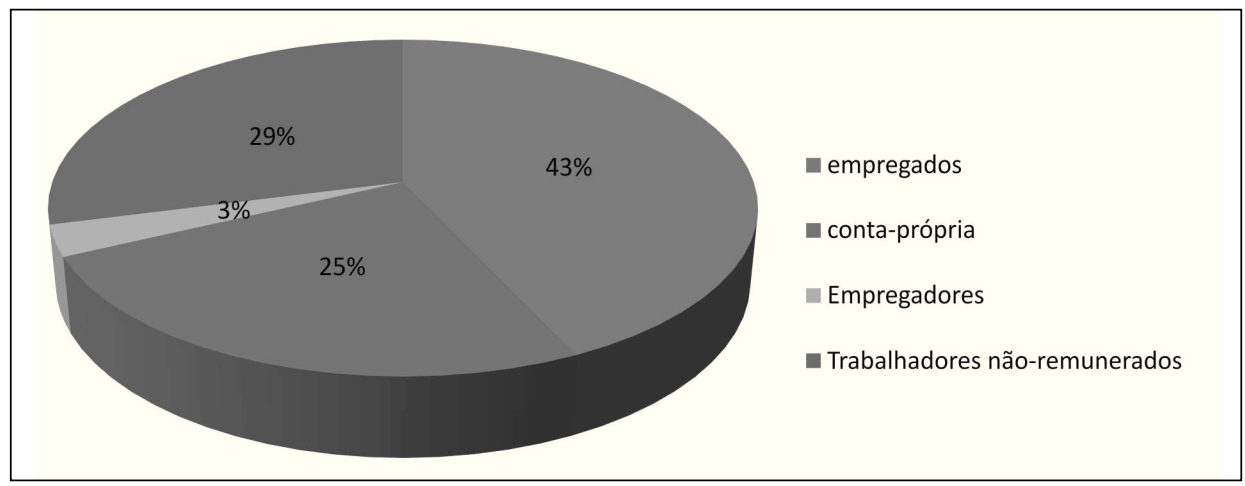

Fonte: Ipea. 
A tabela 2 (que segue abaixo) evidencía a porcentagem de indivíduos com insuficiência severa de renda (IR) e insuficiência severa alimentar (IA) nos anos de 2003 e 2009 por regiões. Compreende-se que em 2003 a insuficiência tanto de renda quanto alimentar são maiores nas áreas rurais no Norte, Nordeste e Sudeste. Atenta-se para o fato de que a situação rural é ainda mais grave na região Norte na qual, em 2003, 40,3\% dos indivíduos enfrentam situação de insuficiência de renda e 24,7\% enfrentam insuficiência alimentar. No Nordeste esse número na área rural é ainda maior, sendo $26 \%$ da população enfrentando problemas de insuficiência alimentar e 51,7\% enfrentando severa insuficiência de renda.

Em 2009, com uma melhoria da distribuição de renda no país, os números de indivíduos que passam por situações de privações diminuem. Nesse ano, no Norte o número de pessoas com insuficiência de renda cai para $28,2 \%$ e com insuficiência alimentar cai para $15,2 \%$ na área rural. No Nordeste a situação continua mais grave, apesar de uma considerável melhora. A porcentagem de indivíduos que enfrentam insuficiência de renda no Nordeste cai para $32 \%$ enquanto o de pessoas que enfrentam insuficiência alimentar cai para $18,1 \%$ na área rural.

Tabela 2- Percentual da população com insuficiência severa de renda (\% IR) e insuficiência severa de alimentos (\% IA) segundo grandes regiões Brasil 2003 e 2009

\begin{tabular}{|l|c|c|c|c|c|c|c|c|}
\hline \multirow{2}{*}{\multicolumn{1}{|c|}{ Região }} & \multicolumn{4}{|c|}{$\mathbf{2 0 0 3}$} & \multicolumn{4}{c|}{2009} \\
\cline { 2 - 9 } & \multicolumn{2}{|c|}{ Urbano } & \multicolumn{2}{c|}{ Rural } & \multicolumn{2}{c|}{ Urbano } & \multicolumn{2}{c|}{ Rural } \\
\cline { 2 - 9 } & \% IR & \% IA & \% IR & \% IA & \% IR & \% IA & \% IR & \% IA \\
\hline Norte & 30.7 & 16.8 & 40.3 & 24.7 & 20.1 & 12.0 & 28.2 & 15.2 \\
\hline Nordeste & 40.7 & 20.4 & 51.7 & 26.0 & 25.8 & 13.5 & 32.0 & 18.1 \\
\hline Sudeste & 25.0 & 14.9 & 25.2 & 15.9 & 17.2 & 9.0 & 19.0 & 10.4 \\
\hline Sul & 17.5 & 8.9 & 15.9 & 5.6 & 11.8 & 6.0 & 11.5 & 5.7 \\
\hline Centro-Oeste & 26.8 & 10.2 & 23.9 & 8.5 & 17.1 & 8.8 & 14.1 & 9.3 \\
\hline TOTAL & $\mathbf{2 8 . 2}$ & $\mathbf{1 5 . 2}$ & $\mathbf{3 7 . 9}$ & $\mathbf{1 9 . 8}$ & $\mathbf{1 8 . 7}$ & $\mathbf{9 . 9}$ & $\mathbf{2 5 . 0}$ & $\mathbf{1 3 . 9}$ \\
\hline
\end{tabular}

Fonte: MAIA; BUAINAIN, 2011. Acesso em 28 jan. 2013.

Por fim, na figura 6 nota-se, principalmente numa análise mais recente do ano 1999 a 2005, diminuições do Índice de Gini, da pobreza e um au- 
mento significativo da renda. A queda da pobreza e do Índice de Gini é notoriamente acentuada a partir do ano de 2003. De 1999 a 2005 é perceptível uma diminuição da pobreza rural em cerca de 10 pontos percentuais. Nesse mesmo período o Índice de Gini teve um decréscimo que deixa evidente a diminuição da desigualdade na zona rural. Para além, a renda nesses 6 anos cresce em cerca de 9 pontos percentuais. Dessa forma é aparente a diminuição da pobreza rural e a melhoria no nível de vida que os individuos dessas regiões levam.

No total, em 2003, na área rural, 37,9\% dos indivíduos enfrentavam situação de insuficiência de renda no Brasil, e 19,8\% da população passava por situação de insuficiência alimentar. Há, em 2009, uma queda nesses números de 12,9 pontos percentuais e 5,9 pontos percentuais, respectivamente. Passando assim a $25 \%$ a proporção de pessoas que enfrentam situação de insuficiência de renda na área rural e $13,9 \%$ de indivíduos que enfrentam insuficiência alimentar na área rural no Brasil.

Figura 6- trajetória da renda, pobreza e da desigualdade nas áreas rurais (Renda em R\$, de setembro de 2006)

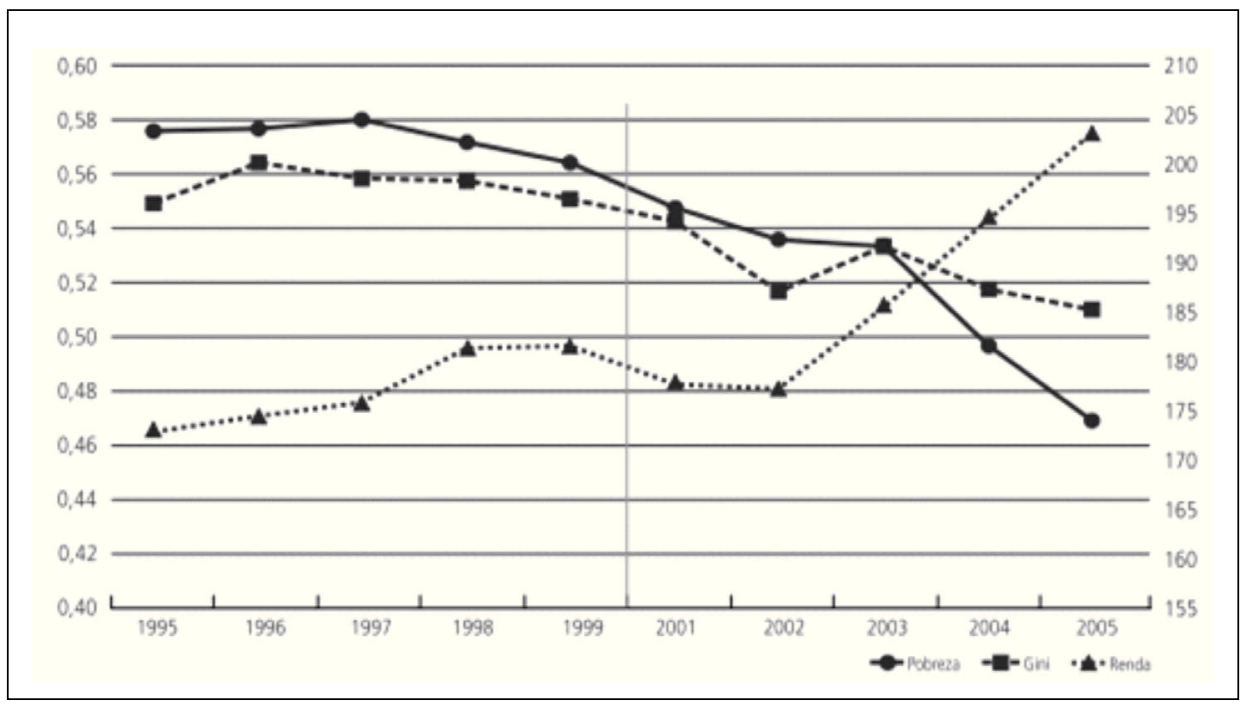

Fonte: Helfand e Del Grossi (2008), apud: Helfand et al.(2009) 
$\mathrm{Na}$ análise dos dados, pode-se percebe que houve redução da desigualdade e da pobreza na zona rural. Mesmo com uma melhoria da renda e diminuição da insuficiência alimentar, a pobreza que assola a população rural ainda é maior que na zona urbana. É inegável, porém, que programas de redistribuição de renda e combate à pobreza como o Bolsa Família e o Fome Zero ajudaram na diminuição das más condições de vida. Além disso, deve-se ressaltar a possibilidade de aposentadoria no meio rural e o PRONAF que servem como auxílio para melhoria de renda e produção dos indivíduos que vivem na área campesina.

\section{CONCLUSÃO}

Em geral, é possível notar que a pobreza rural sofreu uma diminuição entre os anos de 1990 a 2010, com uma queda ainda mais persistente a partir de 2004. Com base nos dados do Instituto de Estudos do Trabalho e da Sociedade, houve uma queda na proporção de pobres de $56,8 \%$ para $23 \%$. Porém aqueles indivíduos que continuaram na situação de pobreza continuam vivendo sem atendimento de suas necesidades básicas e de forma tão precária quanto antes.

É importante salientar que, trantando-se da pobreza de caráter multidimensional, há uma grande insuficiência no acesso de bens e políticas públicas por parte da população pobre do campo. As famílias que se enquadram como pobres rurais têm indicadores abaixo da média no acesso a bens e políticas públicas dos índices gerais. Em 2009, segundo a PNAD, a taxa de analfabetismo na área rural era de cerca de $22 \%$. E mais de $30 \%$ dos indivíduos residentes nessas áres não possuiam acesso à água tratada.

Tanto em relação às estimativas multidimensionais como em relação às abordagens absolutas, pode-se perceber que a desigualdade regional brasileira remonta um cenário de pobreza distinto entre as mesorregiões. O Nordeste apresenta-se com maior concentração de pobres, mostrando assim uma necessidade maior de apoio e políticas públicas de combate da pobreza como problema social.

Os pobres rurais da região nordeste possuem uma taxa de analfabetismo de quase $31 \%$ e a taxa de trabalho infantil chega a pouco mais de $13 \%$. A proporção de indigentes sem acesso a água é de cerca de $57 \%$ e sem acesso a energia elétrica é de $10 \%$. 
Assim, é fato que a ampliação das políticas públicas e dos programas de proteção social de forma a atingirem a população mais necessitada torna-se indispensável. A ampliação do Bolsa Família, dos financiamentos do Programa Nacional de Fomento à Agricultura Familiar (PRONAF), assim como do Plano Brasil sem Miséria surge como necessidade dos pobres e como questão de sobrevivência para os indigentes. É válido lembrar que essa ampliação precisa considerar a exixtência de famílias que não existem oficialmente, ou seja, aquelas famílias cujos indivíduos não possuem, sequer documentos para poderem participar atualmente desses programas.

A análise dos dados desse trabalho leva a compreensão de que a recente queda dos índices de desigualdade no Brasil, em proporções significativas para os agentes de menor renda, mais vulneráveis à miséria, se possibilitou através de políticas públicas de combate à pobreza voltadas a transferência de renda. Com a ampliação do Programa Bolsa Família e com a expansão do sistema de benefícios previdenciários. Estes programas, agindo de forma conjunta potencializaram fortemente a melhoria dos indicadores de renda das famílias na condição de indigência. São, também, os principais responsáveis por ingressos de recursos financeiros nos municípios brasileiros, afetando significativamente os municípios mais pobres, os quais não possuem uma estrutura econômica eficiente, sendo, desta forma, dependentes das transferências governamentais dos programas sociais.

No tocante à ocupação dos indivíduos em relação ao setor da atividade econômica, há uma diminuição na participação dos indivíduos no setor agrícola no valor de 1,12 pontos percentuais entre os anos de 2004 e 2008. Segundo Rocha (2010), isso se deve a um movimento demográfico da população, principalmente no que que diz respeito à incidência de pobreza. Entre 2004 e 2008 pode-se perceber uma diminuição dos pobres na área rural, devido a um contínuo êxodo do campo para a cidade. Há, nesse quinquênio, uma redução da pobreza dada a valorização que teve o piso salarial e a expansão dos benefícios de aposentadoria, principalmente na área rural (Rocha, 2010).

Outrossim, a interrupção da reprodução da pobreza é outro importante aspecto a ser considerado. Impedir que as crianças e jovens de hoje venham a ser as famílias pobres de amanhã é uma forma de se evitar o ciclo da pobreza. Para tanto deve-se investir na educação para que se haja melhor instrução e 
perspectivas de futuros a esses indivíduos. Além de ser necessária a ampliação das oportunidades de inserção no mercado de trabalho, investindo na qualificação desses jovens. Logo, a inserção social, a ampliação do campo de ações das políticas púbicas, assim como uma atenção maior às áreas de maior concentração de pobres são pontos imprescindiveis não só para a diminuição da pobreza como também para o impedimento de sua reprodução.

\title{
DESCRIPTION OF RURAL POVERTY IN BRAZIL: ANANALYSIS FROM 2003 TO 2009
}

\begin{abstract}
This paper describes the rural poverty in Brazil, to do this is used data and maps that show the poverty in the rural area. The analysis ranges from 2003 to 2009 and presents both different approaches and concepts of poverty and its measurement. Following, a case study of Brazil, focusing mainly on the lack of income and food insufficiency, is provided. In the end, a critical analysis of the Brazilian government's social program is made, by questioning if it is successful or not to reducing poverty in the rural areas.

Keywords: Poverty Rural; Income; Brazil.
\end{abstract}

JEL Classification: I3, I32, I38, O1, O15, O18.

\section{REFERÊNCIAS}

COSTA, F. N. Queda da Pobreza e da Desigualdade de Renda do Trabalho no Governo Lula. Cidadania \& Cultura. 2010. p. 1-18. Disponível em: < fernandonogueiracosta.wordpress.com/2010/12/20/queda-da-pobreza-e-da-desigualdade-da-renda-do-trabalho-no-governo-lula/> Acesso em: 28 jan. 2013.

DE HAAN, Arjan. Livelihoods and poverty: The role of migration $\square$ a critical review of the migration literature. The journal of development studies, v. 36, n. 2, p. 1-47, 1999. 
HAGENAARS, A.; DE VOS, K. The definition and measurement of poverty. Journal of Human Resources, p. 211-221, 1988.

HELFAND, Steven M.; ROCHA, Rudi; VINHAIS, Henrique EF. Pobreza e desigualdade de renda no Brasil rural: uma análise da queda recente. Pesquisa e planejamento econômico, v. 39, n. 1, p. 59-80, 2009.

HOFFMANN, Rodolfo. Mensuração da desigualdade e da pobreza no Brasil. UNICAMP - 2003.

HOFFMANN, R. Vinte anos de desigualdade e pobreza na agricultura brasileira. Revista de Economia e Sociologia Rural, Brasília, v. 30, n. 2, p. 96-113, abr.jun.1992

IBGE - Censo 2010; Instituto Brasileiro de Geografia e Estatística. < http:// www.ibge.gov.br/home/estatistica/populacao/censo2010/default.shtm> Acesso em 15 de Jan. e 2012.

KAGEYAMA, A.A.; HOFFMANN,R. Pobreza no Brasil: Uma perspectiva multidimensional. Economia e Sociedade (UNICAMP), v. 15, p. 79-112, 2006.

MAIA, A. G.; BUAINAIN, A. M. Pobreza objetiva e subjetiva no Brasil. Confins. Revista Franco-Brasileira de Geografia. 2011. Disponível em: $<$ http://confins.revues.org/7301>. Acesso em: 30 jan. 2013.

MESTRUM, Francine. Mondialisation et pauvreté: de l'utilité de la pauvreté dans le nouvel ordre mondial. Editions L'Harmattan, 2002.

RIBEIRO, R. A.; NEDER, H. D. Juventude(s): desocupação, pobreza e escolaridade. Nova Economia, v. 19(3), p.475-506, 2009. Disponível em: $<$ web.face.ufmg.br_face_revista_index >.Acesso em: 28 jan. 2013.

ROCHA, S. Pobreza no Brasil. Afinal, de que se trata?. Rio de Janeiro: FGV, 2003. 
ROCHA, S. Crescimento Econômico e Renda. Como ficam os pobres? XXII Forum Nacional do Instituto Nacional de Altos Estudos (INAE). 2010. Disponível em: <www.forumnacional.org.br_pub_ep_EP0349>. Acesso em 29 jan. 2013.

SALAMA, Pierre; DESTREMAU, Blandine. O tamanho da pobreza: Economia política da distribuição de renda. Rio de Janeiro: Garamond, 1999.

SEN, A. Desenvolvimento como Liberdade. Tradução: Laura Teixeira Motta. $2^{\mathrm{a}}$ ed. São Paulo: Companhia das Letras, 2000.

SEN, A. Poverty: an ordinal approach to measurement. Econometrica, v. 44, n. 2, p. 219-231, 1976.

SILVA, J. F. G.; GROSSI, M.E.D.; GASQUES, J.G. ; CONCEIÇÃO, J.C.P.R. Estimativa das famílias potenciais beneficiárias de Programas de Assentamentos Rurais no Brasil. Texto para Discussão (IPEA), Brasília, v. 741, p. 1-22, 2000. 